\title{
Studies on mosquitoes (Diptera: Culicidae) and anthropic environment. 11 - Biting activity and blood-seeking parity of Anopheles (Kerteszia) in South-Eastern Brazil*
}

\section{Estudos sobre mosquitos (Diptera: Culicidae) e ambiente antrópico. 11 - Atividade hematófaga e paridade de Anopheles (Kerteszia) na região Sudeste do Brasil}

\author{
Oswaldo Paulo Forattini, Iná Kakitani, Eduardo Massad and Daniel Marucci \\ Departamento de Epidemiologia, Faculdade de Saúde Pública da Universidade de São Paulo. São \\ Paulo, SP - Brasil (O.P.F., I.K., D.M.), Departamento de Patologia da Faculdade de Medicina, \\ Universidade de São Paulo. São Paulo, SP - Brasil (E.M.)
}

\begin{abstract}
An. (Ker.) cruzii and An. (Ker.) bellator were monitored by the use of human bait and Shannon trap collections during a one-year period in 1994. Indoor and outdoor collections were made on human bait and inside the forest environment a Shannon trap was used. Both were undertaken in the evening crepuscular period. Results showed a greater abundance of An. cruzii in the forest, where as $A n$. bellator was more abundant in the domiciliary environment. Through the application of the Polovodova method an age grading was established. Computing the parous and nulliparous females with Christopher's Stage III and above, more than $30.0 \%$ of blood-seeking specimens of both anophelines had had a previous blood meal. The higher abundance of An. bellator as compared with that of An. cruzii in the domiciliary environment may be explained by the influence of the neighboring low-lying coastal islands of the estuary system.
\end{abstract}

Anopheles, physiology. Ecology, vectors.

\section{Resumo}

Ao longo do periodo anual de 1994 foram realizadas observações sobre a atividade de An. cruzii e An. bellator em isca humana e armadilha de Shannon. Aquela utilizada nos ambientes intra e peridomiciliar, enquanto esta o foi dentro da floresta natural pertencente ao sistema da Mata Atlântica. As coletas foram levadas a efeito concomitantemente, com ritmo quinzenal. A espécie An. cruzii manteve maior abundância no meio florestal mas não no domiciliar, onde An. bellator manteve freqüência de maior endofilia do que aquele. A paridade foi estimada mediante a adoção da técnica de Polovodova. Considerando

* Research sponsored by "Fundação de Amparo à Pesquisa do Estado de São Paulo (FAPESP)" (Grant no. 90/3371-6).

Correspondence to: Oswaldo Paulo Forattini - Núcleo de Pesquisa Taxonômica e Sistemática em Entomologia Médica (NUPTEM). Av. Dr. Arnaldo,

715 - 01246-904 São Paulo, SP. - Brasil Fax: (011) 282.1898 E.Mail: opforati@usp.br

The publication of this article was sponsored by FAPESP (Process 95/2290-6).

Received in 11.16.1995. Approved in: 1.22.1996. 
o conjunto das fêmeas oníparas e das nuliparas, que desenvolveram o estágio III ou além, de Christophers, pôde-se concluir que mais de 30.0\% dos espécimens atraídos pela isca humana devem ter realizado previamente, pelo menos, um repasto sangüineo. A maior abundância de An. bellator pode ser explicada, ao menos em parte, pela influencia da proximidade do sistema de ilhas estuarinas locais.

Anopheles, fisiologia. Ecologia de vetores.

\section{INTRODUCTION}

Some data have already been published on the anophelines of the subgenus Kerteszia in the Ribeira Valley region of S. Paulo State, Brazil (Forattini et $\mathrm{al}^{4}{ }^{4}$, 1993). These mosquitoes are regarded as local malaria vectors in a region which belongs to the Atlantic Rain Forest System. Nevertheless, the factors recognized as determinants of their vectorial capacity are not yet fully known. In the above-mentioned paper, synanthropic and blood-seeking parity patterns were described. The results there reported focused mainly on Anopheles cruzii and An. bellator, the former appearing as the dominant species, both in indoor and outdoor human bait catches. At the same time, information as to general parity conditions and endophagy parameters were obtained.

The length of the gonotrophic cycle, the time between blood meals, is recognized as a relevant transmission factor. As it is environmentally dependent, there is some reason for positing the hypothesis that mosquitoes might have different life spans in different places and/or seasons that would have a bearing on malaria transmission potential. Therefore, age-grading studies are appropriate in the attempt to measure the effects of these external factors (Clements $\left.{ }^{1}, 1992\right)$. Also, by monitoring the age-composition of blood-seeking mosquitoes it should be possible to gather valuable data about the regional potential for malaria endemicity.

A further study, described below, focused on another area in the same region and allowed us to observe the influence of the local environmental on mosquito behaviour by a comparison with the previous study. Parity, seasonal abundance and biting cycle of these species were assessed and the results are presented here.

\section{STUDY AREA}

The present study was conducted on the "Sítio Gentil" (Gentil Farm), the localization of which is given in the map in Figure $1\left(24^{\circ} 79^{\prime} \mathrm{S}\right.$ and $47^{\circ} 66^{\prime}$
W). It is in Cananéia County on the northern shore of the "Mar de Dentro" (Inner Sea) opposite Cananéia Island. The whole area is recognized as a natural undisturbed ecosystem (Hannah et al. $\left.{ }^{10}, 1994\right)$. The environment is representative of the "Mata Atlântica" (Atlantic Rain Forest) covering the slopes of the regional Paratiu Mountain chain that in turn belongs to the "Serra do Mar" (Coastal Mountain Range) system. The anthropic environment is represented only by scattered dwellings along the CananéiaPariquera Açu road, usually located near the forest but without intensive agricultural activities. Facing the study area there is the large "Ilha Comprida" (Long Island) estuary system consisting of several channels, one of them being the "Mar de Dentro", where extensive mangrove vegetation (Rhizophora, Laguncularia) grows in salt marshes. In front of these there are extensive low-lying islands bordering the sea shore in the form of strips, largely covered by woody vegetation called "restinga" (wooded coastal lowland). Mosquito catches were undertaken in the local environment both in a house where the indoor and outdoor catches were made, as well as those which were carried out inside the nearby natural forest (Figs. 1 and 2).

\section{MATERIAL AND METHOD}

Biting activity was monitored fortnightly using two human bait collectors working simultaneously, one of them placed indoors and the other outdoors. Adult mosquitoes were caught as they landed on the collector, during a twohour period starting at sunset. Due to seasonal variation, daily crepuscular data were obtained from the Nautical Almanac tables for local time. Mosquitoes were collected in this manner from January to December 1994.

For purposes of comparison, other adult collections were undertaken at the same time inside the natural forest environment between 17.00 and 20.00 hours by the use of a Shannon trap. It was necessary to establish this schedule, for operational reasons, so as always to include the sunset. Shannon trap collections were routinely performed from June 1993 to April 1995 thus prior and subsequent to the domiciliary collections. 


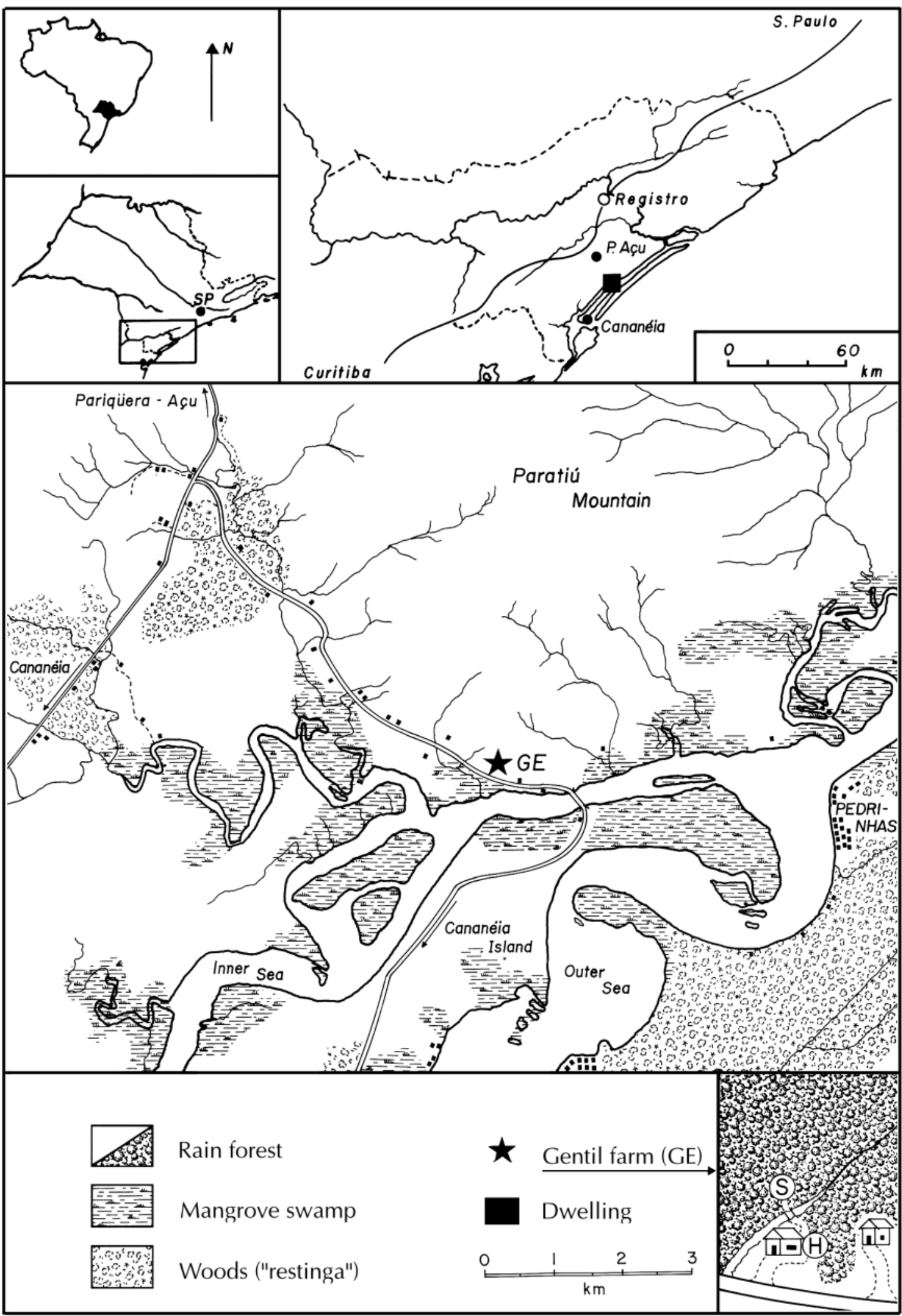

Figure 1 - M ap of the study area showing the location of the G entil Farm (Sítio G entil) and the neighboring ecosystem. Cananéia County, S.Paulo State, Brazil. 


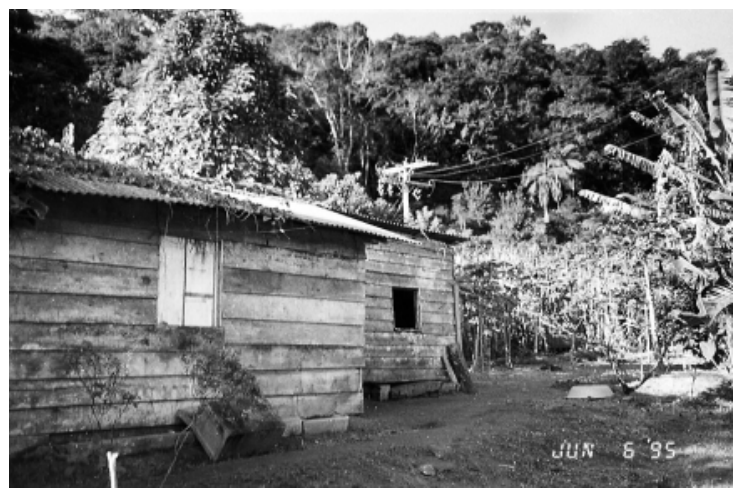

Figure 2 - House of the Gentil Farm (Sítio Gentil) where indoor and outdoor catches were undertaken. The nearby natural rain forest may be seen in the background.

Randomly sampled adult females from the domicile collections were dissected to determine the state of the ovaries and of the follicular stalks. Parity conditions were determined and interpreted in accordance with the traditional technique (Detinova $\left.{ }^{2}, 1962\right)$. Ovarian follicle stages were identified according to Christophers' classification (Clements $\left.{ }^{1}, 1992\right)$. Due to gonotrophic discordance, nulliparous females reaching only stage II were considered as "pre-gravids"(Gillies $\left.{ }^{6,7}, 1954,1955\right)$. Besides these specimens, resting adults collected by the aspiration technique inside the forest environment were also dissected (Forattini et al. ${ }^{5}, 1993$ ). Recently a new model of mosquito oogenesis has been suggested based on original morphological and functional observations (Sokolova $\left.{ }^{11}, 1994\right)$. This model is still subject to discussion and not yet universally accepted.

To express the biting activity, Williams' mean $\left(\overline{\mathrm{X}}_{\mathrm{W}}\right)$ was used as originally described (Haddow $\left.{ }^{8,9}, 1954,1960\right)$. For the collections with the Shannon trap the number of mosquitoes was expressed as an hourly arithmetic mean $\overline{(X)}$. Macroclimatic data concerning rainfall and temperature levels were obtained from the records of the Cananéia Meteorologic Station belonging to the "Instituto Oceanográfico" (Oceanography Institute) of the University of S. Paulo (Fig. 3).

\section{RESULTS}

A total of 24,091 Anopheles (Kerteszia) females were obtained, 7,561 by means of the human bait collections and 16,530 through the use of the Shannon trap, as follows:

\begin{tabular}{|c|c|c|c|c|}
\hline & Human bait & Shannon trap & Total & \\
\hline An. cruzii & $1,795 \quad(23.7 \%)$ & $9,492 \quad(57.4 \%)$ & 11,287 & $(46.9 \%)$ \\
\hline An. bellator & $(76.3 \%)$ & $(42.6 \%)$ & 12,804 & $(53.1 \%)$ \\
\hline Total & $7,561(100.0 \%)$ & $16,530(100.0 \%)$ & 24,09 & $100.0 \%$ \\
\hline
\end{tabular}

As a general yearly rainfall pattern, a wet and a dry period are evident. As shown in Figure 3, the heaviest rainfall occurs from October to April thus

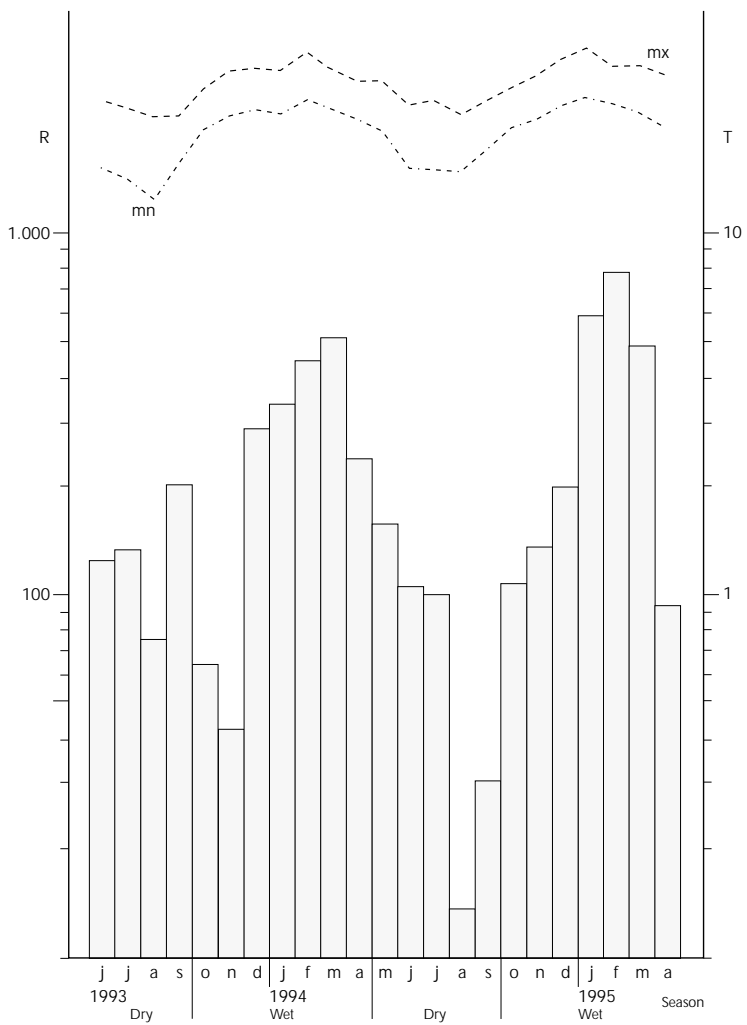

Figure 3 - Meteorological pattern of the study area. $R$ - rainfall $(\mathrm{mm})$ represented by bars.

$\mathrm{T}$ - mean temperatures $(\mathrm{O} C)$, maximal $(\mathrm{mx})$ and minimal $(\mathrm{mn})$.

distinguishing the wet season while May to September correspond to the dry one. Both species were collected during throughout the period but, as was to be expected, with greatest abundance during the wet season, as shown by Figures 4 and 5 .

From the human bait collections, An. bellator's indoor presence (81.1\%) was higher than that of $A n$. cruzii $(18.9 \%)$ as a proportion of the total number of specimens caught (Table 1). Comparing both the indoor and outdoor mosquitoes catches, they varied significantly ( $\left.\mathrm{x}^{2}=33.39 ; \mathrm{P}<0.00000001\right)$. Thus, $A n$. bellator was at least four times more frequent than An. cruzii in the dwelling house environment.

Through hourly arithmetical means it was possible to compare the results obtained under domiciliary conditions, as a whole, with those of the primitive natural forest (Tables 1 and 4). The comparisons of the means showed An. cruzii as predominant in the natural environment, with an annual mean of 60.8 whereas that for An. bellator was 45.1. With respect to the domiciliary environment, An. cruzii's annual mean was 17.3 , thus differing significantly from bellator's $\left(x^{2}=197.97\right.$; $\mathrm{P}<0.00000001)$. 


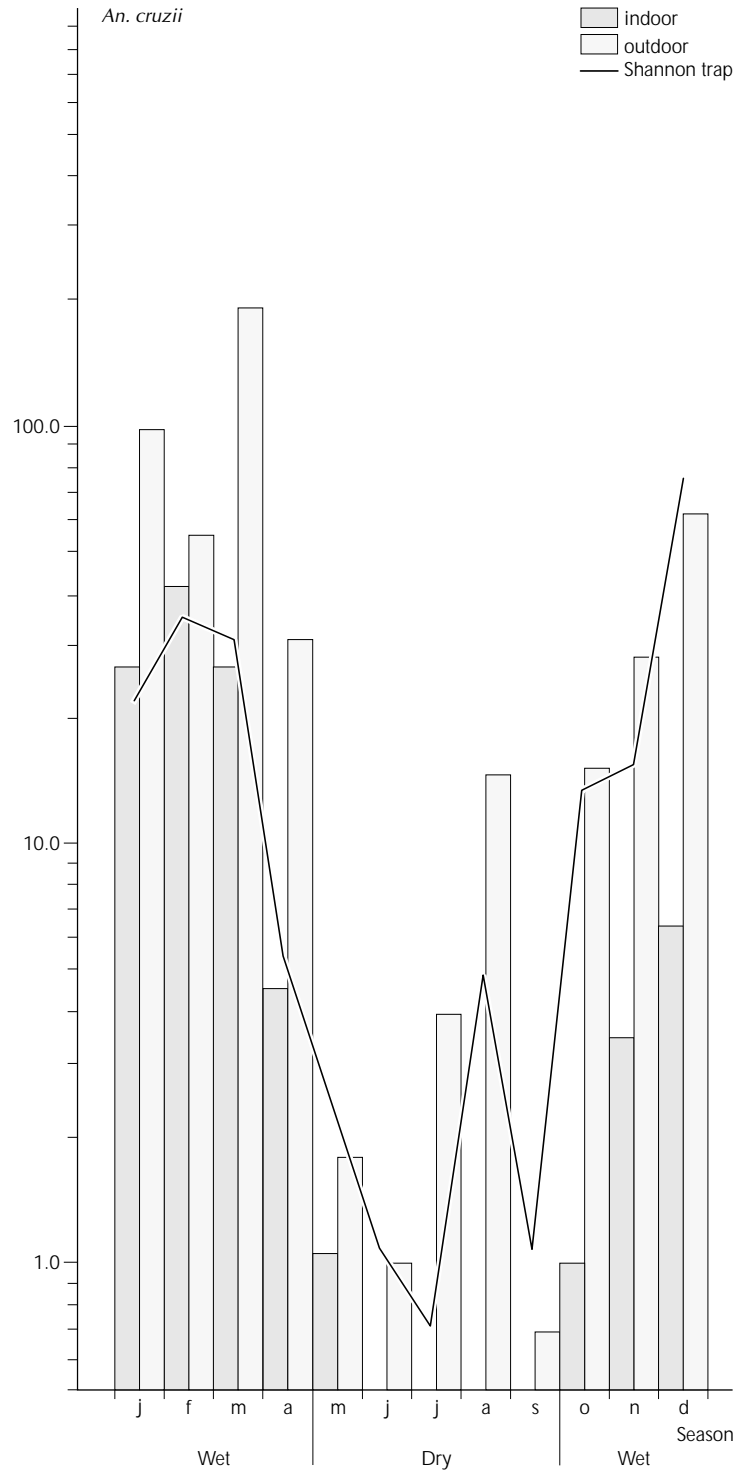

Figure 4 - M onthly captures of $A n$. cruzii on human bait $\left(\bar{X}_{w}\right)$ and by Shannon trap $(\bar{X})$ during 1994.

Data about age composition were obtained through the dissection of $453 \mathrm{An}$. cruzii and 1,552 An. bellator females collected on human bait (Tables 2 and 3). The overall parous (with follicular stalk dilatation) rates were $31.6 \%$ for the former and $27.4 \%$ for the latter species, with no statistically significant difference between them. As regards the capture sites, indoor parity rates were $27.9 \%$ for An. cruzii and $22.9 \%$ for An. bellator, while the outdoor ones were $32.7 \%$ and $29.2 \%$, respectively. That parous distribution was significant only for An. bellator $\left(\mathrm{x}^{2}=6.20 ; \mathrm{P}=0.012772\right)$.

Regarding the resting adults collected by aspiration inside the natural forest environment, 117

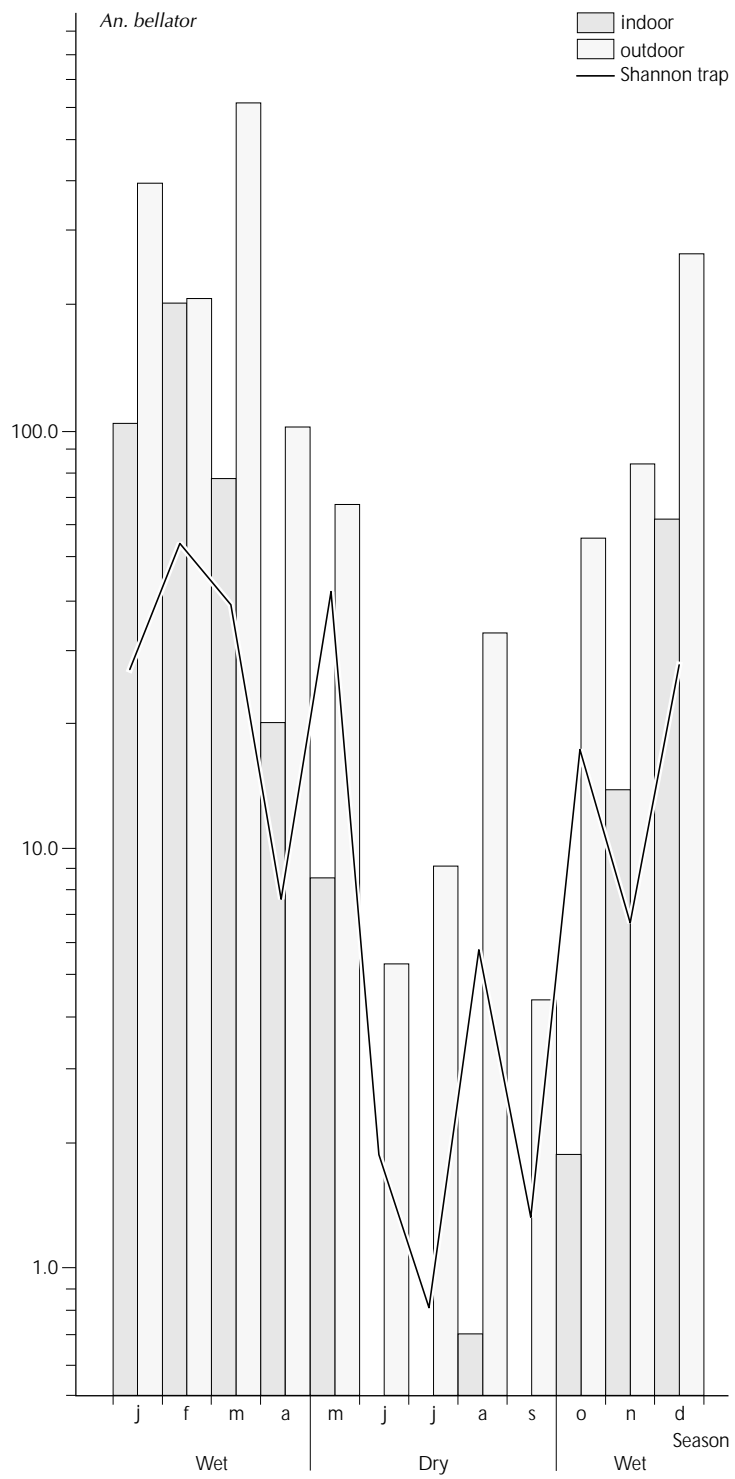

Figure 5 - Monthly captures of $A n$. bellator on human bait $(\mathrm{X})$ and by Shannon trap (X) during 1994.

females were dissected with the following results (abbreviations as in Tables 2 and 3):

\begin{tabular}{lrrrr} 
& PG & NP & $1-\mathrm{P}$ & Total \\
An. cruzii & 68 & 5 & 15 & 88 \\
An. bellator & 16 & 1 & 12 & 29 \\
\cline { 2 - 4 } & 84 & 6 & 27 & 117
\end{tabular}

Thus the parity rates found were $17.0 \%$ for $A n$. cruzii and $41.4 \%$ for An. bellator. Compared to human bait, both species showed significantly different rates $\left(\mathrm{x}^{2}=7.52 ; \mathrm{P}=0.006116\right.$ and $\mathrm{x}^{2}=7.54$; $\mathrm{P}=0.006040$, respectively). However, the two techniques may not be comparable because of sample size and because the host seeking population subset might be different from the overall population. 
Table 1 - M onthly numbers of Anopheles (Kerteszia) females caught landing on human bait at the G entil Farm (January December 1994).

\begin{tabular}{|c|c|c|c|c|c|c|c|c|c|c|c|c|c|c|c|c|}
\hline \multirow{3}{*}{ Months } & \multirow{3}{*}{$\begin{array}{l}\mathrm{N} \text { - } \\
\text { colle- } \\
\text { ctions }\end{array}$} & \multicolumn{4}{|c|}{ An. cruzii } & \multirow{3}{*}{$\mathrm{T}$} & \multicolumn{4}{|c|}{ An. bellator } & \multirow{3}{*}{$\mathrm{T}$} & \multicolumn{4}{|c|}{ Total } & \multirow{3}{*}{ T } \\
\hline & & \multicolumn{2}{|c|}{ Indoor } & \multicolumn{2}{|c|}{ Outdoor } & & \multicolumn{2}{|c|}{ Indoor } & \multicolumn{2}{|c|}{ O utdoor } & & \multicolumn{2}{|c|}{ Indoor } & \multicolumn{2}{|c|}{ Outdoor } & \\
\hline & & $\mathrm{n}$ & $\%$ & $\mathrm{n}$ & $\%$ & & $\mathrm{n}$ & $\%$ & $\mathrm{n}$ & $\%$ & & $\mathrm{n}$ & $\%$ & $\mathrm{n}$ & $\%$ & \\
\hline January & 2 & 59 & 18.7 & 256 & 81.3 & 315 & 213 & 20.4 & 829 & 79.5 & 1,042 & 272 & 20.0 & 1,085 & 80.0 & 1,357 \\
\hline February & 2 & 82 & 36.6 & 142 & 63.4 & 224 & 869 & 52.7 & 781 & 47.3 & 1,650 & 951 & 50.7 & 923 & 49.3 & 1,874 \\
\hline March & 2 & 182 & 28.4 & 458 & 71.6 & 640 & 180 & 16.2 & 932 & 83.8 & 1,112 & 362 & 20.7 & 1,390 & 79.3 & 1,752 \\
\hline April & 2 & 11 & 8.7 & 116 & 91.3 & 127 & 60 & 21.3 & 222 & 78.7 & 282 & 71 & 17.4 & 338 & 82.6 & 409 \\
\hline May & 3 & 8 & 8.4 & 87 & 91.6 & 95 & 73 & 18.6 & 319 & 81.4 & 392 & 81 & 16.6 & 406 & 83.4 & 487 \\
\hline June & 2 & - & - & 2 & $\ldots$ & 2 & - & - & 15 & $\ldots$ & 15 & - & - & 17 & $\ldots$ & 17 \\
\hline July & 2 & - & - & 4 & $\ldots$ & 4 & - & - & 28 & $\ldots$ & 28 & - & - & 32 & $\ldots$ & 32 \\
\hline August & 2 & - & - & 54 & $\ldots$ & 54 & 2 & 2.2 & 89 & 97.8 & 91 & 2 & 1.4 & 143 & 98.6 & 145 \\
\hline September & 2 & - & - & 2 & $\ldots$ & 2 & - & - & 9 & $\ldots$ & 9 & - & - & 11 & $\ldots$ & 11 \\
\hline O ctober & 3 & 4 & 3.9 & 99 & 96.1 & 103 & 12 & 4.6 & 247 & 95.4 & 259 & 16 & 4.4 & 346 & 95.6 & 362 \\
\hline N ovember & 2 & 7 & 9.9 & 64 & 90.1 & 71 & 30 & 14.5 & 177 & 85.5 & 207 & 37 & 13.3 & 241 & 86.7 & 278 \\
\hline December & 2 & 13 & 8.2 & 145 & 91.8 & 158 & 129 & 19.0 & 550 & 81.0 & 679 & 142 & 17.0 & 695 & 83.0 & 837 \\
\hline Total & 26 & 366 & 20.4 & 1,429 & 79.6 & 1,795 & 1,568 & 27.2 & 4,198 & 72.8 & 5,766 & 1,934 & 25.6 & 5,627 & 74.4 & 7,561 \\
\hline
\end{tabular}

Table 2 - Age composition of Anopheles cruzii females collected on human bait at the Gentil Farm and dissected during 1994.*

\begin{tabular}{|c|c|c|c|c|c|c|}
\hline \multirow{3}{*}{$\begin{array}{l}\text { Collection } \\
\text { site }\end{array}$} & \multirow{3}{*}{ Season } & \multicolumn{5}{|c|}{ Dissections } \\
\hline & & \multirow[t]{2}{*}{$\mathrm{n}$} & \multicolumn{2}{|l|}{ Nulliparous** } & \multicolumn{2}{|l|}{ Parous } \\
\hline & & & $P G$ & NP & $1-P$ & $2-P$ \\
\hline \multirow[t]{3}{*}{ Indoor } & Dry (M ay-Sept.) & 8 & 5 & 2 & 1 & - \\
\hline & Wet (Oct.-A pril) & 96 & 64 & 4 & 28 & - \\
\hline & Sub-total & 104 & $69(66.3)$ & $6(5.8)$ & $29(27.9)$ & - \\
\hline \multirow[t]{3}{*}{ Outdoor } & Dry (M ay-Sept.) & 82 & 55 & 5 & 22 & - \\
\hline & Wet (O ct.-A pril) & 267 & 171 & 4 & 91 & 1 \\
\hline & Sub-total & 349 & $226(64.8)$ & $9(2.6)$ & $113(32.4)$ & $1(0.3)$ \\
\hline Total & & 453 & $295(65.1)$ & $15(3.3)$ & $142(31.3)$ & $1(0.2)$ \\
\hline
\end{tabular}

* NP - nulliparous at stage III

PG - pre-gravids (nulliparous at stage II)

I-P - one dilatation (uniparous)

2-P - two dilatations (biparous)

Percentages in parenthesis

**W ithout follicular stalk dilatations.

Table 3 - Age composition of Anopheles bellator females collected on human bait at the Gentil Farm and dissected during 1994.*

\begin{tabular}{|c|c|c|c|c|c|c|}
\hline \multirow{3}{*}{$\begin{array}{l}\text { Collection } \\
\text { site }\end{array}$} & \multirow{3}{*}{ Season } & \multicolumn{5}{|c|}{ Dissections } \\
\hline & & $n$ & Nulliparous** & & Parous & \\
\hline & & & $P G$ & NP & $1-P$ & $2-P$ \\
\hline \multirow[t]{3}{*}{ Indoor } & Dry (M ay-Sept.) & 52 & 37 & 8 & 7 & - \\
\hline & Wet (Oct.-A pril) & 384 & 263 & 28 & 93 & - \\
\hline & Sub-total & 436 & $300(68.8)$ & $36(8.3)$ & $100(22.9)$ & - \\
\hline \multirow[t]{3}{*}{ Outdoor } & Dry (M ay-Sept.) & 260 & 188 & 11 & 61 & - \\
\hline & Wet (O ct.-A pril) & 856 & 579 & 12 & 263 & 2 \\
\hline & Sub-total & 1,116 & 767 (68.7) & $23(2.1)$ & $324(29.0)$ & $2(0.2)$ \\
\hline Total & & 1,552 & $1,067(68.8)$ & $59(3.8)$ & $424(27.3)$ & $2(0.1)$ \\
\hline
\end{tabular}

* NP - nulliparous at stage III

PG - pre-gravids (nulliparous at stage II)

I-P - one dilatation (uniparous)

2-P - two dilatations (biparous)

Percentages in parenthesis

** Without follicular stalk dilatations. 
Table 4 - M onthly collections of Anopheles (Kerteszia) females by the Shannon trap at the Gentil Farm (June 1993 April 1995).

\begin{tabular}{|c|c|c|c|c|c|c|c|c|c|}
\hline \multirow[b]{2}{*}{ Months } & \multicolumn{3}{|c|}{ An. cruzii } & \multicolumn{3}{|c|}{ An. bellator } & \multicolumn{3}{|c|}{ Total } \\
\hline & $\mathrm{n}$ & $\%$ & $\overline{\bar{X}^{*}}$ & $\mathrm{n}$ & $\%$ & $\overline{X^{*}}$ & $\mathrm{n}$ & $\%$ & $\overline{X^{*}}$ \\
\hline January & 1,912 & 20.1 & 63.7 & 599 & 8.5 & 20.0 & 2,511 & 15.2 & 83.7 \\
\hline February & 1,625 & 17.1 & 90.3 & 1,578 & 22.4 & 87.7 & 3,203 & 19.4 & 177.9 \\
\hline March & 1,228 & 12.9 & 40.9 & 1,064 & 15.1 & 35.5 & 2,292 & 13.9 & 76.4 \\
\hline April & 386 & 4.1 & 16.1 & 449 & 6.4 & 18.7 & 835 & 5.1 & 34.8 \\
\hline May & 366 & 3.8 & 20.3 & 748 & 10.6 & 41.6 & 1,114 & 6.7 & 61.9 \\
\hline June & 177 & 1.9 & 5.9 & 80 & 1.1 & 2.7 & 257 & 1.6 & 8.6 \\
\hline July & 303 & 3.2 & 12.6 & 357 & 5.1 & 14.9 & 660 & 4.0 & 27.5 \\
\hline August & 262 & 2.8 & 10.9 & 126 & 1.8 & 5.3 & 388 & 2.3 & 16.1 \\
\hline September & 301 & 3.2 & 12.5 & 181 & 2.6 & 7.5 & 482 & 2.9 & 20.1 \\
\hline October & 1,259 & 13.3 & 42.0 & 1,043 & 14.8 & 34.8 & 2,302 & 13.9 & 76.7 \\
\hline November & 357 & 3.8 & 11.9 & 210 & 3.0 & 7.0 & 567 & 3.4 & 18.9 \\
\hline December & 1,316 & 13.9 & 54.8 & 603 & 8.6 & 25.1 & 1,919 & 11.6 & 80.0 \\
\hline Total & 9,492 & 100.1 & 31.0 & 7,038 & 100.0 & 23.0 & 16,530 & 100.0 & 54.0 \\
\hline
\end{tabular}

As the numbers of females to be dissected were randomly chosen, it was not possible to reach any consistent conclusion about seasonal parity distribution. However, the data suggest a wet season parity increase for both species.

Parity was predominantly represented by the uniparous condition, i.e., the presence of only one follicular stalk dilatation. Nonetheless, about 5.0\% of the females dissected showed nulliparous condition with ovaries developed at Christophers' Stage III. That total consisted of 20 An. cruzii and 60 An. bellator, thus showing that even without previous eggs laid, at least one blood meal had been taken. Females landing on human bait should be considered as blood-seeking. Thus, adding these Stage III nulliparous specimens to the parous ones, it was possible to establish that $34.9 \%$ of the An. cruzii and $31.1 \%$ of the An. bellator females dissected were taking at least a second blood meal.

\section{DISCUSSION}

It is recognized that Kerteszia anophelines are dominant in the primitive Atlantic Rain Forest ecosystem of Southern and South-Eastern Brazil. They are considered as regional malaria vectors, particularly An. cruzii and An. bellator. Observations made in the Ribeira Valley showed that even with exophilic behaviour their presence in human settlements is evident. Despite this, they have no tendency to rest inside dwellings (Forattini et al. ${ }^{3}$, 1990). In earlier research carried out in a neighbouring area named "Sítio Andrade" (Andrade Farm), An. cruzii was the most abundant species caught on human bait. At the same time, An. bellator showed greater endophagy than An. cruzii (Forattini et al. $\left.{ }^{4}, 1993\right)$. In the present research, a similar pattern was found, with An. bellator being four times more frequent in dwellings than An. cruzii. Nevertheless, the collections undertaken inside the forest with the Shannon trap, showed a predominance of An. cruzii, although An. bellator's presence was more significant than that obtained at the "Sítio Andrade" (42.6 and $7.7 \%$, respectively). Thus, judging from this evidence, it seems that An. cruzii, although predominant within the natural environment, do not have the same predominance in the anthropic one where An. bellator is more numerous. The higher adult density of this species, compared with that previously obtained at the "Sítio Andrade", may reflect, at least partially, the influence of the estuary system. This is mainly represented by the low-lying islands the covering vegetation of which consists mainly of scattered woods of stanted trees called "restinga". As is known, An. bellator prefers bromeliads that are more exposed to the sun to those that grow inside the woods on the coastal lowland (Veloso et al. $.^{12}, 1956$ ).

The seasonal patterns followed what is already expected in the Neotropical region. The levels of greatest abundance were observed during the wet season, as the graphs in Figures 4 and 5 show, by the monthly distribution of Williams' means for human bait and the arithmetical hourly ones for Shannon trap collections. There was agreement between the variations, both in the domiciliary and natural environments.

The age compositions obtained through dissections of landing females are certainly valuable indications of previous blood meals. Therefore, the data on the 
parity proportions may be considered as an assessment of the vector capacity. Regarding the indoor and outdoor collections, no significant difference was found for An. cruzii, differently from An. bellator which showed higher parity rates for the outdoor catches. The greater abundance of this species on the Gentil Farm as compared with the Andrade Farm (Forattini et al. $^{4}, 1993$ ) may explain the differences recorded between the two sites. Anyway, the presence of III and further of Christophers' Stages in nulliparous females shows that more than $30.0 \%$ of the bloodseeking specimens of both An. cruzii and An. bellator had taken at least one previous blood meal. Thus, this

\section{REFERENCES}

1. CLEMENTS, A.N. The biology of mosquitoes. London, Chapman \& Hall, 1992. v.1.

2. DETINOVA, T.S. Age grouping methods in Diptera of medical importance, with special reference to some vectors of malaria.Geneva, World Health Organization (WHO Monograph Series, 47), 1962.

3. FORATTINI, O.P.; GOMES, A. de C.; SANTOS, J.L.F.; KAKITANI, I.; MARUCCI, D. Freqüência ao ambiente humano e dispersão de mosquitos Culicidae em área adjacente à mata atlântica primitiva da planície. Rev. Saúde Pública, 24:101-7, 1990.

4. FORATTINI, O.P.; KAKITANI, I.; MASSAD, E.; GOMES, A. de C. Studies on mosquitoes (Diptera: Culicidae) and anthropic environment. 1 - Parity of blood seeking Anopheles (Kerteszia) in South-Eastern Brazil. Rev. Saúde Pública, 27:1-8, 1993.

5. FORATTINI, O.P.; KAKITANI, I.; MASSAD, E.; MARUCCI, D. Studies on mosquitoes (Diptera: Culicidae) and anthropic environment. 4 - Survey of resting adults and synanthropic behaviour in South-Eastern Brazil. Rev. Saúde Pública, 27:398-411, 1993.

6. GILLIES, M. T. The recognition of age-groups within populations of Anopheles gambiae by the pre-gravid rate and the sporozoite rate. Ann. Trop. Med. Parasitol., 48:58-74, 1954. strongly suggests that there is the necessity for multiple blood feeding for a first clutch of eggs to be developed, i.e., as a consequence of a gonotrophic discordance, at least initially.

In conclusion, An. bellator keeps its higher endophily level as compared with that of An. cruzii. Otherwise, this latter mosquito mantains greater abundance within the natural environment, particularly in the rain forest covering the mountain slopes. In addition, there is evidence that no initial gonotrophic development occurs but that about $30.0 \%$ of blood-seeking females of both species had already taken at least one blood meal.

7. GILLIES, M. T. The pre-gravid phase of ovarian development in Anopheles funestus. Ann. Trop. Med. Parasitol., 49:320-5, 1955.

8. HADDOW, A. J. Studies on the biting-habits of African mosquitoes and appraisal of methods employed, with special reference to the twenty-four-hour catch. Bull. Entomol. Res., 45:199-242, 1954.

9. HADDOW, A. J. Studies on the biting-habits and medical importance of east African mosquitoes in the genus Aedes. I - Subgenera Aedimorphus, Banksinella and Dunnius. Bull. Entomol. Res., 50:759-79, 1960.

10. HANNAH, L.; LOHSE, D.; HUTCHINSON, C.; CARR, J.L.; LANKERANI, A. A preliminary inventory of human disturbance of World ecosystems. Ambio, 23:246-50, 1994.

11. SOKOLOVA, M.I. A redescription of the morphology of mosquito (Diptera: Culicidae) ovarioles during vitellogenesis. Bull. Soc. Vector Ecol., 19:53-68, 1994.

12. VELOSO, H.P.; MOURA, J.V. de; KLEIN, R.M. Delimitação ecológica dos anofelíneos do subgênero Kerteszia na região costeira do sul do Brasil. Mem. Inst. Oswaldo Cruz, 54:517-47, 1956. 